Parasitaxus parasitized: Novel infestation of Parasitaxus usta (Podocarpaceae).

\author{
Seyfullah, Leyla
}

2017-08

Seyfullah , L, Beimforde , C , Perrichot , V , Rikkinen , J \& Schmidt , A 2017 , ' Parasitaxus parasitized: Novel infestation of Parasitaxus usta (Podocarpaceae). ' , Arthropod - Plant Interactions , vol. 11 , no. 4 , pp. 507-514 . https://doi.org/10.1007/s11829-016-9494-0

http://hdl.handle.net/10138/309430

https://doi.org/10.1007/s11829-016-9494-0

unspecified

acceptedVersion

Downloaded from Helda, University of Helsinki institutional repository.

This is an electronic reprint of the original article.

This reprint may differ from the original in pagination and typographic detail.

Please cite the original version. 


\title{
Parasitaxus parasitized: novel infestation of Parasitaxus usta (Podocarpaceae)
}

Leyla J. Seyfullah ${ }^{1}$, Christina Beimforde ${ }^{1}$, Vincent Perrichot ${ }^{2}$, Jouko Rikkinen ${ }^{3,4}$, Alexander R. Schmidt ${ }^{1}$

1 Department of Geobiology, University of Göttingen, Goldschmidtstraße 3, 37077 Göttingen, Germany

2 CNRS UMR 6118 Géosciences \& OSUR, Université Rennes 1, 263 avenue du Général Leclerc, 35042 Rennes, France 3 Finnish Museum of Natural History, University of Helsinki, P.O Box 7, 00014 Helsinki, Finland

4 Department of Biosciences, University of Helsinki, P.O. Box 65, 00014 Helsinki, Finland

\begin{abstract}
The world's sole 'parasitic' gymnosperm Parasitaxus usta (Podocarpaceae) is endemic to the island of Grande Terre, New Caledonia. It is a threatened species because of its limited geographic range and progressing habitat fragmentation. Here, we report a novel scale insect outbreak on a Parasitaxus sub-population from Monts Dzumac in the southern part of Grande Terre. The identity of the scale insect was determined through combining morphological and molecular methods. The field collection of scale insects and their secretions from infested Parasitaxus specimens allowed morphological identification of the superfamily Coccoidea. Subsequent genetic sequencing using CO1 markers allowed phylogenetic placement of the wax scale insects to the genus Ceroplastes (Coccoidea, Coccidae), a widespread pest genus. The identified species, C. pseudoceriferus, has not been previously recorded from New Caledonia. As Parasitaxus is already vulnerable to extinction, this new threat to its long-term survival needs to be monitored. Other New Caledonian endemic plant species are potentially at risk of this new species, although it was not observed on Falcatifolium taxoides, the host of Parasitaxus.
\end{abstract}

Keywords Ceroplastes, Coccoidea, New Caledonia, Parasitaxus usta, Podocarpaceae, Scale insects 


\section{Introduction}

Parasitaxus usta (Vieillard) de Laubenfels is unique since it is the only heterotrophic gymnosperm species known, and both it and its host tree, Falcatifolium taxoides (Brongniart and Gris) de Laubenfels, are podocarpalean conifers endemic to New Caledonia's largest island, Grande Terre (de Laubenfels 1959; Sinclair et al. 2002).

Parasitaxus is a small, monoecious understorey shrub reaching a maximum of $1.8 \mathrm{~m}$ tall, with a trunk up to $3 \mathrm{~cm}$ wide, which has no green parts despite having chlorophyll in the shoots and foliage (Feild and Brodribb 2005). Parasitaxus is instead anthocyanic (Cherrier et al. 1992), with reddish-purple branches that have small thick scale leaves (de Laubenfels 1959; Köpke et al. 1981; Cherrier et al. 1992; Woltz et al. 1994; Sinclair et al. 2002).

The nature of the relationship between Parasitaxus and Falcatifolium is unique among parasitic plants (Feild and Brodribb 2005). Parasitaxus grows out of the roots or rarely from the lower trunk of its host conifer (Sinclair et al. 2002; Feild and; Brodribb 2005) and is defined as parasitic in relation to host water exploitation as Parasitaxus has root-like sinkers that develop basally and grows into the host's bark. These sinkers contain xylem that clasp the host's root vascular cambium and occasionally form direct xylem connections (Cherrier et al. 1992; Woltz et al. 1994; Feild and Brodribb 2005). This method of directly tapping into the host's xylem is similar to xylem-exploiting angiosperm parasites, but Parasitaxus lacks the photosynthetic capability, despite having chloroplasts with significant amounts of chlorophyll (Feild and Brodribb 2005).

In terms of carbon capture, Parasitaxus is a mycoheterotroph, not a parasite (Feild and Brodribb 2005). A filamentous fungus infests each plant with appresoria and vesicular arbuscles (Woltz et al. 1994, Feild and Brodribb 2005) and can form mats with fruiting bodies on Falcatifolium roots and the below-ground portion of Parasitaxus (Cherrier et al. 1992; Woltz et al. 1994). The fungus is found in the xylem parenchyma and tracheids of Falcatifolium and the tracheids of Parasitaxus (Cherrier et al. 1992; Woltz et al. 1994) as well as in the attachment site between the two conifers (Cherrier et al. 1992; Woltz et al. 1994; Feild and Brodribb 2005). This is an internal fungal network linking the vasculatures of the two plant species, unlike all other mycoheterotrophic plants which use mycorrhizal fungi in the soil (Feild and Brodribb 2005).

Parasitaxus is only found in the deep shade of the forest floor in the dense humid evergreen rainforest at altitudes between 100 and $1100 \mathrm{~m}$ on serpentine soils in association with its host (Jaffré 1995), but it does not occur in all Falcatifolium taxoides localities (Sinclair et al. 2002). The 
IUCN reports that Parasitaxus is "vulnerable" to extinction in the wild because of its limited geographic range that is severely fragmented with continuing decline in both the extent and quality of habitat and the number of mature plants, whereas F. taxoides is listed as "least concern" with stable populations. Key threats to Parasitaxus are from mining, the increase in fires, and an overall loss of suitable habitat (Thomas 2010). Parasitaxus requires primary forest and is not known to survive or establish in secondary forests. It is also very sensitive to disturbance caused by tourists and others visiting the areas where it occurs (Thomas 2010). Seedlings are unknown in the wild, and no successful germination or grafting on to the host in cultivation is known (Sinclair et al. 2002).

Here, we report a novel, currently localized infestation of a Parasitaxus sub-population by Ceroplastes Gray, a wax scale insect. Scale insects pierce into the phloem to feed on plants, physically damaging their host and causing nutrient depletion, whilst producing honeydew; a substrate for sooty mould growth (Ben-Dov 1997). Additionally, Ceroplastes has been shown experimentally to acquire and transmit plant viruses (Mahfoudhi et al. 2009), although there is no morphological evidence of virus-transmission to Parasitaxus, but this Ceroplastes species has not been previously reported from New Caledonia, so its infestation of a rare endemic plant is a concern for the long-term survival of this species and potentially other endemic New Caledonian plants. Consequently, we suggest monitoring the populations of this iconic species.

\section{Materials and methods}

\section{Field collection}

Whilst surveying the vegetation of Monts Dzumac, about $14 \mathrm{~km}$ north of Dumbéa, $\left(22^{\circ} 01^{\prime} 50.94^{\prime \prime} \mathrm{S}\right.$ $166^{\circ} 28^{\prime} 03.42^{\prime \prime} \mathrm{E}$, elevation $900 \mathrm{~m}$ ) in southern New Caledonia, plants of this particular population of Parasitaxus were found to have abnormal bright structures on their dark branches (Fig. 1b-f), which were caused by an infestation of scale insects (Hemiptera: Coccoidea). The infested plants were photographed and samples of the insects and their residues collected on November 15th, 2011, for lab analysis and preserved in $80 \%$ ethyl alcohol for storage and transport. The insects and residues were examined with light microscopy and then some insects were sampled for DNA sequencing to allow identification. 


\section{Phylogenetic analysis}

For phylogenetic analysis, we used the main subunit of the cytochrome c oxidase complex (CO1). DNA was isolated from the scale insect on Parasitaxus by following the instructions of QIAamp DNA Minikit (Qiagen) for small tissue amounts. Gene-specific PCR reactions were carried with the primers COI Ron (F) or COI-RLR (F) (Simon et al. 1994) and COI Calvin (R) (Lin and Wood 2002). PCR was performed according to the protocols listed in the respective references for the mentioned primers. PCR products were purified using PCRapace (Invitek, Berlin, Germany). All PCR products were sequenced in both directions with a MegaBACE 1000 automated sequencing machine and DYEnamic ET Primer DNA Sequencing Reagent (Amersham Biosciences, Little Chalfont, UK). Sequences were assembled and edited using Seaview 4 (Gouy et al. 2010).

For phylogenetic assignment of the scale insect from Parasitaxus (Fig. 2), 20 additional sequences were downloaded from Genbank. The resulting taxon set comprises $19 \mathrm{CO} 1$ genes of representatives of the family Coccidae and two $\mathrm{CO} 1$ genes of Pseudococcidae, which were used as outgroups. For subsequent intraspecific analysis (Fig. 3), we downloaded CO1 sequences of Ceroplastes ceriferus and C. pseudoceriferus from the study of Deng et al. (2012). Resulting taxon sampling included all available $\mathrm{CO} 1$ sequences of $C$. pseudoceriferus. Accession numbers of all sequences utilized in this study are provided in the phylogenetic trees of Figs. 2 and 3, respectively. The nucleotide sequence from the novel scale insect has been assigned to GenBank accession number KM102757.

Both datasets were aligned in SeaView version 4 (Gouy et al. 2010) after translating the nucleotide alignments into protein code using the mitochondrial genetic code for invertebrates as implemented in SeaView. In this way, we monitored the quality of the Genbank sequences, since stop codons appear to point to frameshifts or false nucleotides. Sequences were subsequently retranslated into the nucleotide code and gene regions for phylogenetic analyses were selected using Gblocks (Castresana 2000). For calculating phylogenetic relationships of Coccidae (Fig. 2), the best fitting substitution model was chosen from seven substitution schemes included in the software package jModeltest 2.1.1 (Darriba et al. 2012). Models were chosen according to the Bayesian information criterion (BIC, Schwarz 1978), which supported the $\operatorname{TrN}+\mathrm{I}+\mathrm{G}$ model as the best fit for the $\mathrm{CO} 1$ dataset. For comparing $\mathrm{CO} 1$ genes of $\mathrm{C}$. ceriferus and $\mathrm{C}$. pseudoceriferus (Fig. 3), the GTR model was applied allowing MrBayes to estimate substitution rates and nucleotide frequencies. 
Bayesian analyses were carried out using Markov chain Monte Carlo (MCMC) in MrBayes 3.1.2 (Ronquist and Huelsenbeck 2003) conducting four chains for 10 million generations each, sampling parameters every 1,000th generation. All analyses were performed on the freely available computational resource CIPRES (http://www.cipres.org). Average standard deviations of split frequency (ASDSF) lower than 0.01 were interpreted as indicative of independent MCMC convergence. CO1 data matrixes, settings for the Bayesian analyses and resulting phylogenetic trees (Figs. 2, 3) were uploaded to TreeBASE, direct access: http://purl.org/phylo/treebase/ phylows/study/TB2:S20327.

Sequence divergence between Ceroplastes pseudoceriferus from Parasitaxus and other $C$. pseudoceriferus specimens were calculated by comparing 386 nucleotides and by applying Kimura's two parameter model (K2P; Kimura 1980) implemented in Mesquite version 3.11 (http://mesquiteproject. org).

\section{Results}

\section{Field observations}

A well-known and fairly easy accessible population of Parasitaxus (Fig. 1a) is found at Monts Dzumac. At this locality nearest the path, we observed several Parasitaxus with evidence of an infestation; this sub-population had five Parasitaxus individuals of different ages including two juveniles, and one dead adult plant (Fig. 1g). About $20 \mathrm{~m}$ further north from this path the larger population of 15 individuals had no apparent signs of infestation.

Branches of Parasitaxus are normally reddish-purple with small thick scale leaves (Fig. 1a), but some of the plants were covered with an irregular distribution of dull, whitish-cream masses 4-8 $\mathrm{mm}$ long and 3-6 mm high (Fig. 1b). The masses have a waxy-looking appearance (Fig. 1b-d) and correspond to the coating secreted by adult female scale insects (Hemiptera: Coccoidea) thought to be for defence and weather protection (Tamaki et al. 1969; Tamaki 1997). When the masses are removed from the branches, a concavity is revealed, the bottom of which is the ventral surface of the adult female scale insect which contains numerous juvenile insects inside (Fig. 1e). Freeliving sub-adult scale insects were also noted over the branches (Fig. 1f).

A mature-looking plant was found dead (Fig. 1g), with the waxy masses present, in the infested sub-population, and in the close-by sub-population another dead small individual was 
found that did not have the waxy masses present (this specimen was further from the path). We were unable to determine the cause of death and left the plants in situ and undisturbed. The individuals of the host plant Falcatifolium taxoides and other species of plants close to the infested Parasitaxus showed no signs of infestation.

\section{Scale insects}

The adult female morphology is largely concealed beneath the wax cover which roughly resembles a tortoise carapace or an oyster shell (Fig. 1b-d). Similarly, very few morphological structures are visible inside the concavity except very short legs which are usually no longer used by the adult female. The remaining structures are mostly hidden by numerous (>30) instar larvae (Fig. 1e). Removal of the cover was attempted in order to reveal the sole adult female's cuticular morphology, as this is key to distinguishing species; however, it was not successful.

\section{Phylogenetic placement of scale insects}

According to phylogenetic signals of the main subunit of the cytochrome c oxidase complex (CO1), the sampled scale insects parasitizing Parasitaxus usta clearly belong to the genus Ceroplastes Gray (Fig. 2). Included species of the genus Ceroplastes are definitely supported as a monophyletic clade (support 1.0 pp). Within Ceroplastes, the scale insect found on Parasitaxus is most closely related to Ceroplastes pseudoceriferus Green (1.0 pp), the Indian wax scale, according to the available $\mathrm{CO} 1$ sequences in Genbank, and the next most closely related species is $C$. ceriferus Fabricius. This means that the sampled scale insects are part of a large pest genus that is found worldwide and are most likely to be $C$. pseudoceriferus, based on our combined morphological and phylogenetic analyses since the divergence (K2P) between the $\mathrm{CO} 1$ sequences of $C$.

pseudoceriferus and the scale insect found on Parasitaxus is $1.3 \%$, which is far below the mean interspecific divergence of scale insects of $12.2 \%$ and the interspecific divergence between $C$. ceriferus and C. pseudoceriferus of 5\% found by Deng et al. (2012).

As Ceroplastes pseudoceriferus shows slight intraspecific variation within the $\mathrm{CO} 1$ gene (Deng et al. 2012), we further compared our sequence with all available CO1 sequences of $C$. pseudoceriferus (and further C. ceriferus sequences), all deriving from China (Deng et al. 2012). The analysis shows that our scale insect differs slightly from Chinese $C$. pseudoceriferus specimens. Furthermore, Fig. S1 shows that the CO1 gene of the New Caledonian scale insect varies at other gene positions, which do not overlap with the intraspecific gene variation of Chinese $C$. 
pseudoceriferus specimens. We double-checked our sequence and guarantee a very good quality of the sequence chromatogram of the utilized gene region. Still, according to the K2P divergence of $1.3 \%$ between $\mathrm{CO} 1$ sequences from the scale insect on Parasitaxus and remaining $C$. pseudoceriferus from China, the New Caledonian scale insect belongs to the species $C$. pseudoceriferus.

\section{Discussion}

The Coccidae is one of the most species diverse families within the superfamily Coccoidea. Resolving the relationships of their constituent genera and species is challenging and was not the intent of our phylogeny, since our taxon set only comprises 21 species in total. However, the genus Ceroplastes was strongly supported as being monophyletic in our Bayesian calculation (Fig. 2). We propose that Parasitaxus usta is parasitized by the wax scale insect $C$. pseudoceriferus. Morphological identification of the Coccidae is very problematic since the species appear very similar and the distinctive morphological features are only visible in the adult females, but not always (Gullan and Kosztarab 1997).

There are about 140 species of Ceroplastes, with two species, C. ceriferus and C. rubens Maskell being reported from New Caledonia, but to date $C$. pseudoceriferus is not yet mentioned as a pest in New Caledonia. Ceroplastes pseudoceriferus is an important pest of mango in Taiwan and Bangladesh, where heavy infestations cause wilting of the leaves and flowers, malformation of flowers, and failure of twigs to produce flowers, thus reducing plant vigour and cropping. We believe that this pest has recently jumped host to Parasitaxus, since we only discovered a subset of one population with the infestation. Of the two species that are known to occur in New Caledonia, $C$. rubens is apparently the most widespread Ceroplastes species on Grande Terre. It infests various species in Annona, Citrus, Ficus, Eugenia, Mangifera, Musa, Persea, Psidium, Cocos, Barringtonia, Cycas, Gerbera, Hibiscus, Lagerstroemia, Plumeria, Calophyllum, Agathis, Melaleuca, Montrouziera, Schinus, and Thespesia (Brun and Chazeau 1986). Ceroplastes ceriferus is highly polyphagous (it is found on more than 122 plant species in 46 families across the world), and it occurs only on stems and branches. The scale insects can cause dieback of stems and wilting, and reduced vigour of the plants. Severe infestations disfigure plants because of the large numbers of white scales and provides copious honeydew on which sooty moulds develop. In New Caledonia, it 
is known to infest Citrus spp, Melaleuca quinquenervia, and Montrouziera (Brun and Chazeau 1986). Eight countries are reported to have C. pseudoceriferus present: Bangladesh, China, India, Japan, Palau, South Korea, Sri Lanka, and Taiwan (see ScaleNet: Scale Insects (Coccoidea) Database, http://scalenet.info). Due to the lack of molecular data available on Ceroplastes pseudoceriferus from other areas across the world, our study is unable to show where this pest originated, or how it got to New Caledonia. However, the differences between the CO1 genes of $C$. pseudoceriferus from Parasitaxus and remaining specimens from China (Fig. 3) suggests that this pest possibly did not come from China, or at least has not recently been transferred from China to New Caledonia.

The fact remains that this Ceroplastes species is now present in a primary forest and poses a threat to the long-term vigour of Parasitaxus, a unique gymnosperm that is already deemed vulnerable to extinction. Food is imported to New Caledonia, so it is very possible that this pest arrived with fruit or vegetable material and has spread, and this might be how the other Ceroplastes species would have arrived. The presence of the infestation close to the best accessible population of Parasitaxus also might explain its occurrence. The rest of the same Parasitaxus population about $20 \mathrm{~m}$ further away from the path (which is likely rarely visited) showed no signs of infestation, so it is possible that humans or other vectors brought infested material (plant-based foods or materials) with them and facilitated the Ceroplastes host-jump.

\section{Outlook}

Based on our observations of the Parasitaxus foliage, there is no evidence so far of virustransmission by the pest which would cause noticeable abnormalities in the tissues, so this is not an immediate cause for concern. However, given that we believe that the pest has only recently infested Parasitaxus, we are concerned for the long-term health and vigour of the various fragmented populations of this vulnerable species as Ceroplastes is shown to reduce the general vigour of its hosts. We believe that the populations of Parasitaxus should be closely monitored to assess the spread of this Ceroplastes species to understand how much of a threat this new pest poses to Parasitaxus and other endemics, and whether control measures are necessary or even possible. 


\section{Acknowledgements}

We thank Jérôme Munzinger (Montpellier) and Kerstin Schmidt (Jena) for help in the preparation of our fieldwork in New Caledonia. Fieldwork and collection in southern New Caledonia were kindly permitted by the Direction de l'Environnement (Province Sud), permit no 17778/DENV/SCB delivered in November 2011. Support for L.J.S. was provided by the Dorothea Schlözer program, Göttingen. Partial support for fieldwork was provided to V. P. by Grant OSUR (Univ. Rennes 1) from program AO1.P4.

\section{Electronic supplementary material}

The online version of this article (doi:10.1007/s11829-016-9494-0) contains supplementary material, which is available to authorized users.

\section{References}

Ben-Dov Y (1997) Diagnosis 3-4 in Soft scale insects: their biology, natural enemies and control. Volume 7A. In Ben-Dov Y, Hodgson CJ (Eds); Soft scale insects: their biology, natural enemies and control. Elsevier Science Publishers, Amsterdam, Netherlands, Volume 7A, pp. xxiv +452 pp.

Brun LO, Chazeau J (1986) Catalogue des ravageurs d'interet agricole de Nouvelle-Caledonie. 2e edition. ORSTOM, Noumea

Castresana J. (2000) Selection of conserved blocks from multiple alignments for their use in phylogenetic analysis. Mol Biol Evol 17:540-552

Cherrier J-F, Gondran M, Woltz P, Vogt G (1992) Parasitisme interspécifique chez les gymnospermes; données inédites chez deux Podocarpaceae endémiques NéoCalédoniennes. Revue de cytologie et de biologie végétales - Le Botaniste 15:65-87

Darriba D, Taboada GL, Doallo R, Posada D (2012) Jmodeltest 2: more models, new heuristics and parallel computing. Nat Methods 9:772

De Laubenfels d J (1959) Parasitic conifer found in New Caledonia. Science 130:97

Deng J, Yu f, Zhang TX, Hu HY, Zhu CD, Wu SA, Zhang YZ (2012) DNA barcoding of six Ceroplastes species (Hemiptera: Coccoidea: Coccidae) from China. Molecular Ecol Resour 12:791-796 
Field TS, Brodribb TJ (2005) A unique mode of parasitism in the conifer coral tree Parasitaxus ustus (Podocarpaceae). Plant Cell Environ 28:1316-1325

Gullan PJ, Kosztarab M (1997) Adaptations in scale insects. Ann Rev Entomol 42:23-50

Gouy M, Guindon S, Gascuel O (2010) Seaview version 4: a multiplatform graphical user interface for sequence anignment and phylogenetic tree building. Mol Biol Evol 27:221-224

Jaffré T (1995) Distribution and ecology of the conifers of New Caledonia. In: Enright NJ, Hill RS (eds) Ecology of the southern conifers, Smithsonian press, Washington, DC, USA, pp. 171196

Kimura M (1980) A simple method for estimating evolutionary rates of base substitutions through comparative studies of nucleotide sequences. J Mol Evol 16: 111-120

Köpke E, Musselman IJ, De Laubenfels DJ (1981) Studies on the anatomy of Parasitaxus ustus and its root connections. Phytomorphology 31:85-92

Mahfoudhi N, Digiaro M, Dhouibi MH (2009) Transmission of grapevine leafroll viruses by Planococcus ficus (Hemiptera: Pseudococcidae) and Ceroplastes rusci (Hemiptera: Coccidae). Plant Dis. 93:999-1002

Lin CP, Wood TK (2002) Molecular phylogeny of the North American Enchenopa binotata (Homoptera: Membracidae) species complex. Ann Entomol Soc Am 95:162-71

Ronquist F, Huelsenbeck JP (2003) Bayesian phylogenetic inference under mixed models. Bioinformatics 19:1572-1574

Schwartz G (1978) Estimating the dimension of a model. Ann. Stat. 6: 461-464.

Simon C, Frati F, Beckenbach A, Crespi B, Liu H, Flook P (1994) Evolution, weighting, and phylogenetic utility of mitochondrial gene sequences and a compilation of conserved polymerase chain reaction primers. Ann Entomol Soc Am 87:651-701

Sinclair WT, Mill RR, Gardner MF, Woltz P, Jaffre T, Preston J, Hollingsworth ML, Ponge A, Moller M (2002) Evolutionary relationships of the New Caledonian heterotrophic conifer, Parasitaxus usta (Podocarpaceae), inferred from chloroplast trnL-F intron/spacer and nuclear rDNA ITS2 sequences. Plant Syst Evol 233:79-104

Schwarz G (1978) Estimating the dimension of a model. Ann Stat 6:461-464

Tamaki Y (1997) Chemistry of the Test cover. 55-72 in Soft scale insects: their biology, natural enemies and control. Volume 7A. In Ben-Dov Y, Hodgson CJ (eds) Soft scale insects: their biology, natural enemies and control; Elsevier Science Publishers, Amsterdam, Netherlands, Volume $7 \mathrm{~A}$, pp. xxiv $+452 \mathrm{pp}$. 
Tamaki Y, Yushima T, Kawai S (1969) Wax Secretion in a Scale Insect, Ceroplastes pseudoceriferus Green (Homoptera : Coccidae). Appl Entomol Zool 4:126-134

Tautz D, Hancock JM, Webb DA, Tautz C, Dover GA (1988). Complete sequences of the rRNA genes of Drosophila melanogaster. Mol Biol Evol 5:366-376

Thomas P (2010) Parasitaxus usta. In: The IUCN Red List of Threatened Species 2010:

e.T31002A9597883. http://dx.doi.org/10.2305/IUCN.UK.2010-3.RLTS.T31002A9597883.en. Downloaded on 09 June 2016.

Urban JM, Cryan JR (2007) Evolution of the planthoppers (Insecta: Hemiptera: Fulgoroidea). Mol Phylogenet Evol 42:556-572

Von Dohlen CD, Moran NA (1995) Molecular phylogeny of the Homoptera: a paraphyletic taxon. J Mol Evol 41:211-223

Woltz P, Stockey RA, Gondran M, Cherrier JF (1994) Interspecific parasitism in the gymnosperms: unpublished data on two endemic New Caledonian Podocarpaceae using scanning electron microscopy. Acta Bot Gallica 141:731-746 


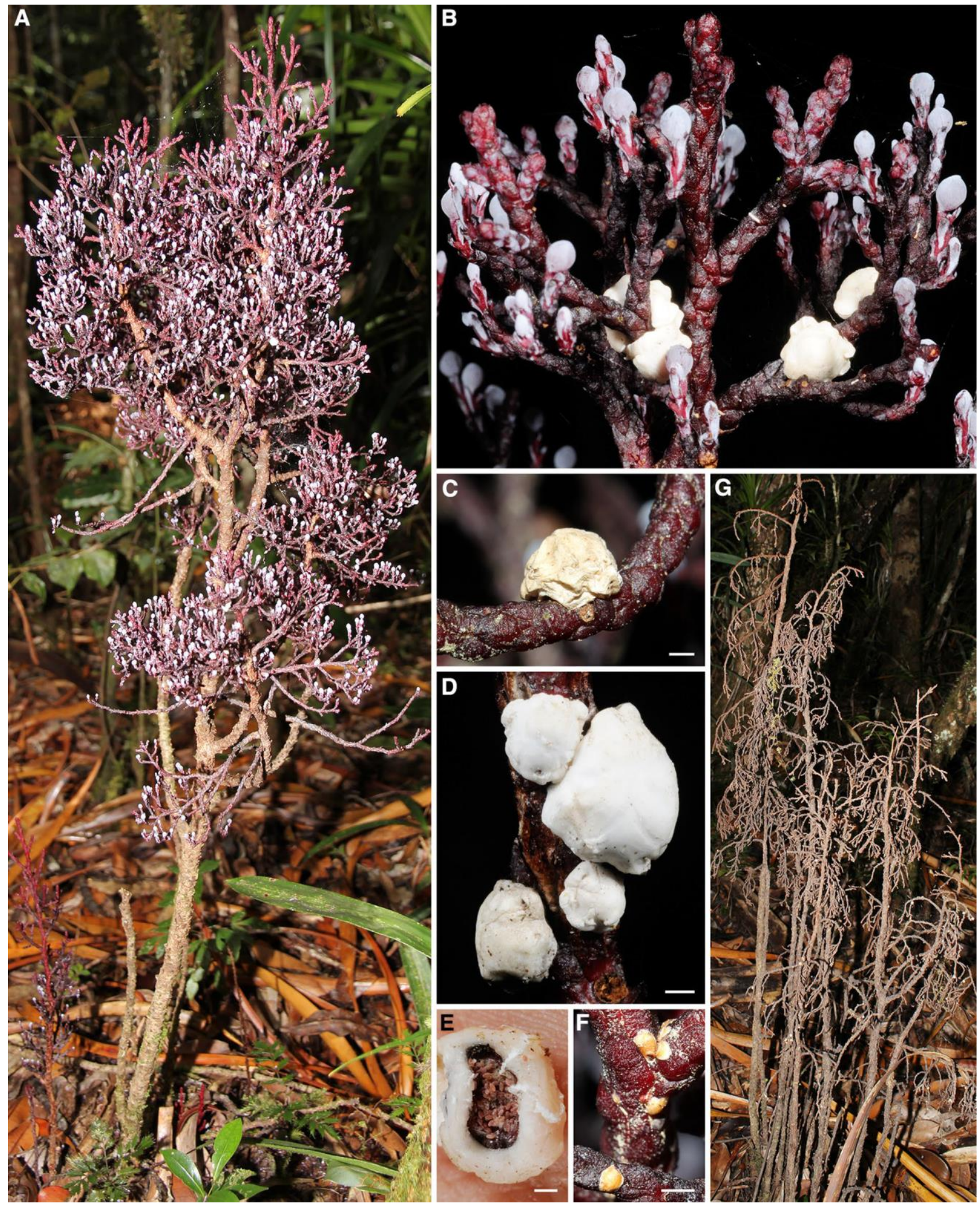

Fig. 1 Parasitaxus usta (Podocarpaceae) sub-population from Monts Dzumac, New Caledonia,

infested by Ceroplastes (Coccidae) scale insects. Scale bars are $1 \mathrm{~mm}$. a Mature specimen with anthocyanic branches and shoots and light grey immature seed cones growing in deep shade, with 
a mild infestation. $\mathbf{b}$ Appearance of the infested uppermost part of a plant, the yellow-white waxy masses are the defensive structures of the female scale insects, the grey ovoid structures are immature seed cones. c A darker yellowish mass on a lower branch, perhaps indicating an older female insect mass. d Several white masses of varying dimensions on a lower branch. e The internal concavity of one of the masses with numerous instar larvae hiding the female scale insect. f Free-living sub-adult scale insects on the shoots. $\mathbf{g}$ Dead adult plant, with signs of infestation on the lower portion of the stems 


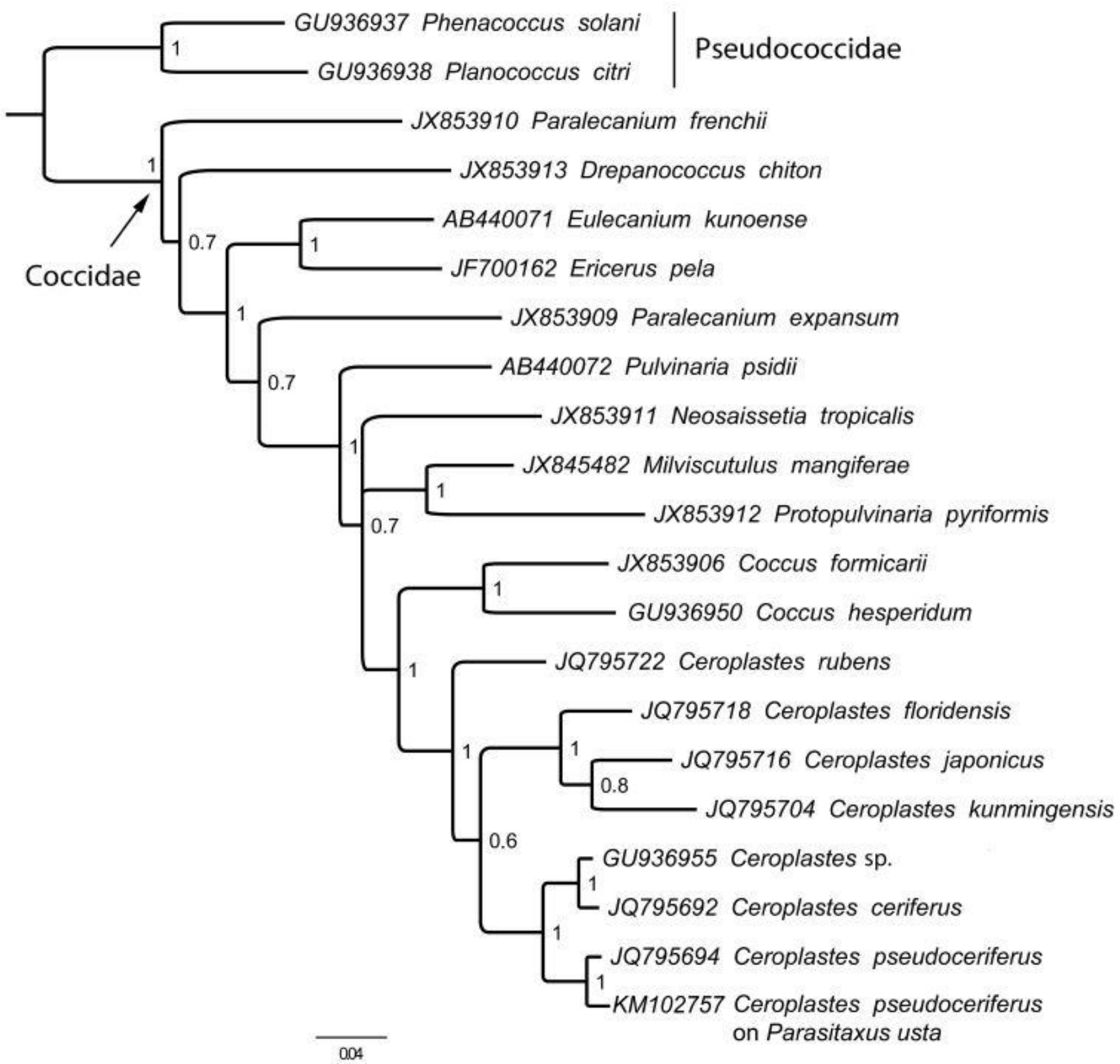

Fig. 2 Molecular phylogeny of various scale insects based on the CO1 marker gene and Bayesian analysis. The scale insect discovered on Parasitaxus from Monts Dzumac is Ceroplastes pseudoceriferus, meaning a novel infestation of this plant and of New Caledonia. Numbers indicate the branch support (posterior probability, p.p.) and the line indicates the substitution rate along the branches. GenBank accession numbers precede genus names 


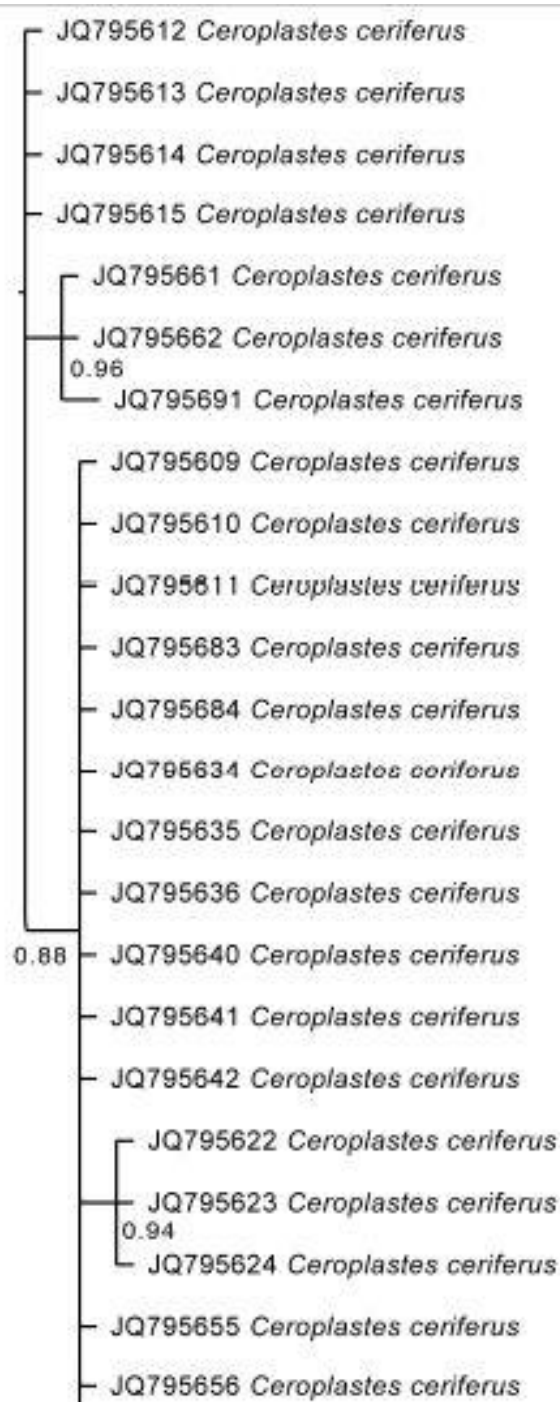

- JQ795656 Ceroplastes ceriferus

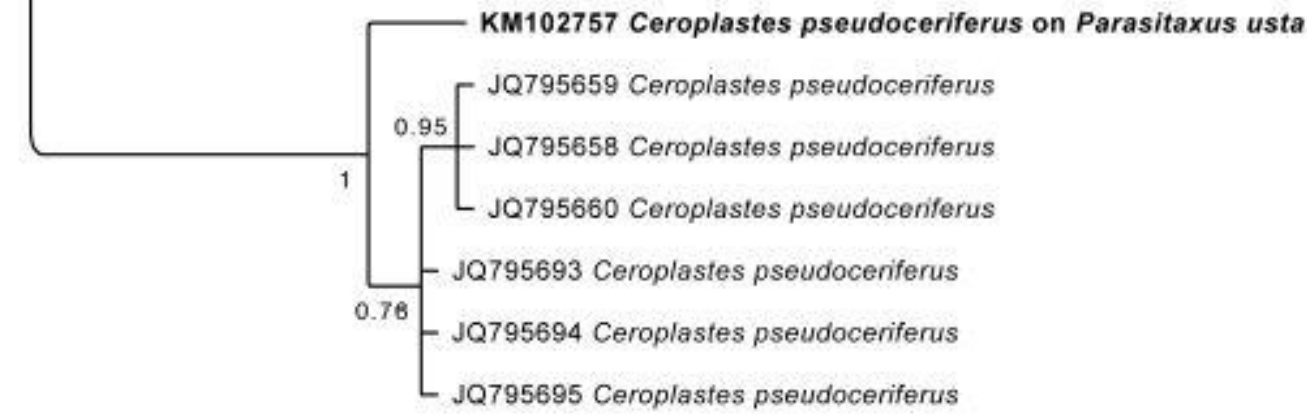

0.0060

Fig. 3 Molecular phylogeny based on sequence clusters of Ceroplastes ceriferus and $C$. pseudoceriferus from the CO1 marker gene and Bayesian analysis. The scale insect on Parasitaxus from Monts Dzumac clusters with $C$. pseudoceriferus, but is distinct from Chinese $C$. pseudoceriferus. Numbers indicate the branch support (posterior probability, p.p.) and the line indicates the substitution rate along the branches. GenBank accession numbers precede genus names 